\title{
Tamaño del distrito y voto estratégico en España
}

\author{
Cristina Moreno \\ Universidad de Murcia \\ cmoreno@um.es \\ Pablo Oñate \\ Universidad de Valencia \\ pablo.onate@uv.es
}

RESUMEN

En este estudio se analizan los efectos psicológicos del sistema electoral, prestándose atención a la influencia del tamaño o magnitud del distrito electoral en la utilización estratégica del voto en las elecciones del Congreso de los Diputados. Para medir la incidencia del voto estratégico en el comportamiento de los votantes españoles entre 1982 y 2000 se aplican los diversos enfoques propuestos para estudiar este fenómeno. Los resultados permiten afirmar que la variable institucional constituida por el sistema electoral —el tamaño o la dimensión del distrito, o sea, la diferencia entre distritos grandes y pequeños- influye en el comportamiento de los electores.

Palabras clave: Voto Estratégico, Voto Útil, Comportamiento Electoral, Sistema Electoral, Elecciones. 


\section{EL VOTO ESTRATÉGICOY SU ESTUDIO}

El estudio de los sistemas electorales en sus diversas facetas, así como el de sus consecuencias para los respectivos sistemas políticos, viene siendo un tema habitual en Ciencia Política en las últimas décadas. No sería demasiado arriesgado decir que la cuestión del sistema electoral, sus efectos y eventual reforma es uno de los temas principales en los debates sobre la reforma de los sistemas político-institucionales contemporáneos.

Al estudiar las consecuencias de los sistemas electorales, Duverger (1972 [e. o. 1951]: 252) distinguió entre efectos mecánicos y efectos psicológicos de los mismos. Los primeros se proyectan directamente sobre el sistema de partidos respectivo, reduciendo su fragmentación, al sobrerrepresentar a los partidos más votados y penalizar, infrarrepresentándolos, a los que menos apoyo logran en las urnas. Se trata, por tanto, de efectos reductores (Sartori, 1994: 32) que despliegan sus consecuencias en la operación del reparto de escaños, después de la votación. En cambio, los efectos psicológicos no influyen directamente en el sistema de partidos, sino en las elites partidistas y en los electores: implican una adaptación del respectivo comportamiento y estrategia política a los efectos mecánicos o reductores que el sistema electoral tiene en el sistema de partidos. Esos efectos psicológicos llevarían a las elites partidistas, en buena lógica de estrategia electoral, a alcanzar alianzas preelectorales para beneficiarse de la sobrerrepresentación que el sistema suele conferir a las formaciones más votadas, escapando de los sesgos reductores que soportan las que recaban menos apoyo entre los electores. Este tipo de efectos no siempre ha tenido un fuerte impacto en las elites partidistas españolas, a juzgar por su comportamiento a lo largo de buena parte de la reciente historia electoral ${ }^{1}$.

La proyección de los efectos psicológicos sobre los electores les lleva a anticiparse a las consecuencias (efectos mecánicos) que el sistema electoral va a provocar al transformar los votos en escaños, adaptando su decisión de voto a esos efectos previstos: quienes se sienten cercanos a un pequeño partido y estarían dispuestos a votar por él, adaptan su comportamiento electoral a partir de la sospecha — más o menos fundamentada - de que, dado el escaso apoyo electoral que logrará, esa formación por la que optarían en primer lugar no va a conseguir representación (debido a los sesgos desproporcionales del sistema electoral, especialmente severos para los partidos pequeños). Algunos de estos electores pueden votar por un partido que prefieren en segundo lugar, del que no se sienten tan cercanos, pero que sí tiene opciones efectivas de conseguir el escaño. Al objeto de lograr que su voto no sea desperdiciado, estos votantes instrumentales adaptarán estratégicamente

\footnotetext{
1 El estudio del efecto psicológico sobre las elites partidistas supera las ambiciones de estas páginas, en las que nos limitare-
} mos a estudiar las consecuencias del sistema electoral en los electores. 
su comportamiento a los efectos mecánicos del sistema electoral para evitar tal despilfarro. Con ello, el elector no sólo consigue estar representado por un partido del que, en cierta medida al menos, se siente afín (es su second best), sino que en ocasiones se resta fuerza a una tercera opción política situada en el otro lado del espectro ideológico de la competición electoral, beneficiando a la orientación política de la que se siente más cercano. Este tipo de comportamiento se ha denominado voto estratégico, voto sofisticado o voto útil, y da lugar a un efecto constrictivo (Sartori, 1994: 32) que se produce antes de la votación, afecta a la distribución del voto y refuerza, indirectamente, los efectos mecánicos que luego se derivarán de la operación de transformar los votos en escaños².

La incidencia de los efectos mecánicos y psicológicos está indirectamente relacionada con la proporcionalidad del sistema electoral. Así, en los sistemas mayoritarios la intensidad de estos efectos será mucho mayor que en aquellos de carácter proporcional. Atendiendo al grado en el que unos y otros se manifiesten, Sartori (1994: 37) propuso clasificar los sistemas electorales en un continuum que iría desde los sistemas débiles a los sistemas fuertes, en función de la medida en la que condicionen o modelen el resultado de la votación ${ }^{3}$.

Los numerosos estudios que han abordado en las últimas dos décadas la cuestión de los sistemas electorales y sus consecuencias han concentrado su atención en los efectos mecánicos, dejando de lado los efectos psicológicos, dadas las mayores dificultades para su medición y su menor influencia (directa) sobre el sistema de partidos resultante de cada proceso

2 En la formulación inicial de sus propuestas, Duverger consideró que el voto estratégico era propio de los sistemas electorales mayoritarios (dada la intensidad reductora de sus efectos mecánicos), mientras que era inexistente en los proporcionales. Sartori (1968: 278) precisó que la diferencia entre ambos tipos de sistema electoral era —respecto de los efectos psicológicos - cuantitativa, no cualitativa. En igual sentido, ver Colin Leys, «Models, Theories and the Theory of Political Parties», Political Studies, 7, 1959 (139), cit. en Cox (1997: 31). Una de las primeras formulaciones del efecto psicologico puede encontrarse en W. P. Shively, «The Elusive Psicological Factor: A Test for the Impact of Electoral Systems on Voter's Behavior», Comparative Politics, 3, 1970 (115-125). Shively (1970: 117) describía el fenómeno del voto estratégico de la siguiente forma: «cuando hay pocas probabilidades de que un partido gane [representación] en un distrito, será menos probable que los votantes sigan optando por él o, si no le habían votado previamente, que le voten por vez primera». Taagepera y Shugart (1989: 65) hablan, más que de efecto psicológico, de «actitud psicológica» que lleva a los votantes de partidos que quedan sin representación «a dejar de votarles por considerar que es un voto desperdiciado». Blais y Carty (1991: 79), en un sentido similar, entienden que el efecto psicológico hace referencia a la «tendencia de los votantes que, dándose cuenta de que los votos a partidos minoritarios no se transforman en escaños, optan por votar a la opción que consideran menos inaceptable de las dos principales». En este sentido, cabe pensar que habrá más tendencia a votar estratégicamente a medida que la competitividad electoral (incertidumbre sobre el resultado) aumente. La competitividad o margen de la victoria de un partido sobre su inmediato competidor ( $y$, a nuestros efectos, margen para que la victoria sea por mayoría absoluta o no) es un atributo de la competencia democrática, un estado concreto del juego democrático (Sartori, 1987: 261 y 262).

3 En esta misma obra (1994: 37 ss.), Sartori nos recuerda que los sistemas electorales no son el único factor que influye o condiciona el comportamiento de los votantes, sino que también la cultura política y el propio sistema de partidos afectan a sus decisiones. De forma similar, Cox (1997: 5 y passim) atiende, además de a las instituciones electorales, a las motivaciones políticas y las expectativas públicas. No podemos detenernos aquí en estas cuestiones. En las páginas que siguen nos limitaremos a tratar de dar cuenta de la medida en que los efectos psicológicos sobre los votantes han estado presentes en las elecciones del Congreso de los Diputados en España. 
electoral ${ }^{4}$. No obstante, se han propuesto diferentes procedimientos para medir su presencia, si bien ninguno de ellos es del todo satisfactorio cuando se aplica al caso español. Por ello, en estas páginas se aplicarán todos ellos de forma complementaria, en un intento de alcanzar la mejor comprensión de la extensión del fenómeno del voto estratégico en España.

El enfoque más sencillo consiste en comparar la fragmentación electoral (acudiendo al índice del número efectivo de partidos) de diversos sistemas políticos con distinto sistema electoral o analizar las diferencias en cuanto a esa variable en aquellos sistemas políticos que han pasado de un tipo de sistema electoral a otro (Blais y Carty, 1991: 82). Este enfoque puede aplicarse también a sistemas que, como el español, cuentan con distritos de muy desigual magnitud y, por ende, registran dispares niveles de proporcionalidad ${ }^{5}$. $\mathrm{Al}$ agrupar los distritos en distintos tipos en función de su respectivo tamaño, no se prioriza su orientación política ni su ubicación geográfica. Si atendemos estrictamente al número de escaños que se reparten en su seno, cabe pensar que resultarán agrupados distritos con muy diferentes tendencias electorales: en principio, el único vínculo entre ellos es el número de escaños a repartir, pudiendo estar ubicados en áreas geográficas bien distintas y tener una orientación política muy diferente. No obstante, podría alegarse que estos distritos o circunscripciones comparten perfiles sociodemográficos similares: población mayoritariamente rural, con baja densidad demográfica o dispersa en núcleos poco poblados. En todo caso, también cabe aducir que la tendencia hacia la heterogeneidad que la variable regional imprime en el respectivo sistema o subsistema de partidos en muchos de nuestros distritos (Oñate y Ocaña, 2000) difumina el posible efecto de ese perfil común. Por todo ello, cabe considerar que si las circunscripciones pequeñas dan muestras de alguna pauta común que las distingue claramente de las grandes en cuanto al índice del número efectivo de partidos, ésta deberá ser explicada por su magnitud o tamaño, sin que la tendencia política o la ubicación geográfica sean significativas.

Otra de las propuestas para medir la presencia de voto estratégico fue elaborada por Gunther (1989), quien utilizó encuestas de opinión en las que se preguntaba a los votantes por sus preferencias partidistas, así como por la opción a la que habían votado en la anterior elección ${ }^{6}$. Aplicando este enfoque al caso de las elecciones generales españolas de 1979

\footnotetext{
${ }^{4}$ En este sentido se manifestaban Taagepera y Shugart (1989: XIV) cuando sostenían que el efecto psicológico sigue siendo en gran medida elusivo.
}

5 No consideramos necesario detenernos aquí en la incidencia que la magnitud o tamaño del distrito, esto es, el número de escaños que se reparten en su seno, tiene en la proporcionalidad. Puede verse al respecto Oñate y Ocaña (1999: 54 ss.).

6 Gunther tuvo en cuenta las encuestas realizadas por Data S.A. después de las elecciones de 1979 y 1982 . Pero hay que tener en cuenta que las peculiaridades de esas convocatorias bien pudieron haber influido en los resultados observados: en 1979 sólo se había celebrado previamente una elección, que además estuvo rodeada de la confusión propia de su carácter fundacional, ofreciendo el aspecto de una sopa de letras a unos inexpertos electores. Con esos escasos precedentes, difícilmente podían intuir los españoles los efectos que se derivarían del sistema electoral para las pequeñas formaciones. La con- 
y 1982, Gunther detectó que quienes manifestaban tener claras preferencias partidistas por formaciones que ocupaban el tercer o cuarto lugar, votaban a esas mismas formaciones en mucha menor medida en los distritos pequeños que en los grandes, entendiendo que esa peculiaridad se debía a que los votantes de los distritos pequeños intuían y anticipaban los considerables sesgos desproporcionales y reductores derivados del sistema electoral en su distrito, que dejarían sin representación a su primera opción. Esos votantes de los distritos pequeños sabían o sospechaban —en opinión de Gunther- que si optaban por la pequeña formación de la que se sentían más cercanos, desperdiciarían su voto. Este autor concluía que buena parte de ellos acababan votando por un partido del que no se sentían tan cercanos, pero que sí tenía opciones reales de lograr un escaño. Los votantes de los distritos grandes que se sentían próximos a esas mismas formaciones pequeñas tendían a concederles su voto en mucha mayor medida (el doble, según Gunther, 1989: 84 ss.) que los de los pequeños.

Cox (1997: 116) consideraba que esta propuesta adolecía de serias deficiencias derivadas de la extraordinaria capacidad que presuponía en los electores españoles para intuir con precisión ex ante los resultados electorales y los cálculos que habría que hacer para atribuir el último escaño del distrito; esto es, para detectar de antemano qué partidos serían el primer y segundo perdedor, y con qué margen, al dilucidarse el último escaño del distrito. Esta crítica cobra mayor importancia cuando está referida a unos electores cuya experiencia con el sistema electoral se reduce a uno o dos procesos previos y de carácter fundacional. No obstante, cabe pensar que, salvadas estas últimas circunstancias y después de haber observado durante varios procesos electorales las consecuencias que reiteradamente se han derivado del sistema electoral para esas pequeñas formaciones en la operación de transformar los votos en escaños en esos distritos de magnitud reducida, y a la luz de lo que auguran los sondeos preelectorales para el partido del que se sienten cercanos, los ciudadanos están en condiciones de intuir que esa pequeña formación no va a lograr representación. No podrán, seguramente, anticipar los sofisticados cálculos que la fórmula D'Hondt implica para repartir el último escaño, pero su intuición acerca de las escasas posibilidades de que su formación preferida consiga representación no parece mera especulación.

El tercer enfoque metodológico para registrar la presencia de voto estratégico nace con la propuesta de Cox (1997: 85 ss. y 103 ss.), algo más sofisticada y consistente en la comparación del valor que alcanza en distintos distritos el índice SF (second/first), que viene dado

vocatoria de 1982 adoptó el perfil de unos comicios de naturaleza excepcional, por la profunda crisis política en la que se enmarcó su celebración y los resultados que se produjeron. Ambas circunstancias, y las variables difícilmente controlables de ellas derivadas, recomendarían elegir otros procesos electorales para medir la incidencia del sistema electoral en la decisión de los votantes. 
—para un sistema electoral como el español_ por la ratio resultante de dividir el cociente de votos de la segunda lista perdedora por el de los de la primera lista perdedora al realizarse el reparto del último escaño en cada distrito ${ }^{7}$. Cox parte de dos posibles situaciones (ideales) en cada uno de éstos: la de equilibrio duvergeriano, en la que, dada la distribución habitual del voto, sólo dos partidos tienen posibilidades efectivas de lograr representación, siendo el apoyo de las otras opciones mucho menor (la competición electoral suele darse solamente entre los dos partidos más votados). En los distritos en los que se registra esta pauta de competición encontraremos una distribución generalmente unimodal del índice SF, con una tendencia al 0: en este tipo de distritos los resultados electorales serán considerablemente predecibles respecto de las terceras y sucesivas fuerzas políticas (en el sentido de que no lograrán representación), por lo que puede anticiparse que la presencia del voto estratégico será significativa, mayor cuanto más ajustada se anticipe la victoria.

En cambio, en una situación de desequilibrio duvergeriano, los terceros y sucesivos partidos compiten efectivamente con los dos primeros por obtener representación, siendo menos previsible el resultado del reparto de escaños. Los terceros y cuartos partidos cuentan con posibilidades reales de obtener algún acta de diputado, por lo que el presupuesto para la utilización estratégica del voto desaparece. Como también Gunther comprobaba, el uso estratégico del voto apenas tiene razón de ser en los distritos medianos y grandes. La no utilización estratégica del voto se manifestará en una distribución del índice SF de carácter unimodal con frecuencias más abundantes en torno al valor 1 .

Como es obvio, la situación de equilibrio duvergeriano es propia de ámbitos en los que el sistema electoral genera considerables sesgos desproporcionales (sistemas mayoritarios o proporcionales impuros en distritos pequeños), mientras que la de desequilibrio duvergeriano se dará allá donde el sistema propicie mayores niveles de proporcionalidad (sistemas proporcionales puros). Desde esta lógica, si en un sistema proporcional impuro, como el español, se agregan los valores del índice SF atendiendo al tamaño pequeño o grande de los distritos y para un conjunto de elecciones sucesivas, cabrá interpretar que las diferencias entre las tendencias de las distribuciones del índice de uno y otro grupo de distritos se deben a la utilización estratégica del voto, evidenciándose su presencia en los distritos pequeños por distribuciones distintas de las observadas como promedio de todos los distritos o de los distritos grandes. En términos generales, cabe pensar que, para el conjunto del territorio, la existencia de distritos de diversa magnitud, así como la pluralidad de pautas de competición electoral dentro de los mismos (en algunos, terceros y cuartos partidos compiten con éxito con los primeros y logran representación), darán lugar a una distribución de frecuencias del índice SF de carácter bimodal. No obstante, el predominio de un tamaño de

\footnotetext{
7 Como es lógico, el valor del índice SF oscila entre 0 y 1.
} 
distrito pequeño y la competición entre sólo dos partidos (mayores probabilidades de utilización del voto estratégico) se manifestará en una distribución de frecuencias del índice SF (con tendencia a una distribución unimodal con acumulación de casos en torno al valor 0 ) distinta de la registrada en los distritos grandes (más bien de carácter bimodal o unimodal con clara acumulación de casos en torno al valor 1 ).

\section{EL VOTO ESTRATÉGICO EN ESPAÑA}

Como es sabido, el sistema electoral español se caracteriza por dar lugar a unos altos niveles de desproporcionalidad, que han llevado a que se haya rechazado la calificación de sistema proporcional para referirse a él, adoptándose la más certera de sistema mayoritario atenuado (Montero y Vallés, 1992: 7; Oñate y Ocaña, 1999: 51 ss.). La combinación de unos distritos de magnitud media considerablemente reducida (6,7 escaños de promedio) con la fórmula D'Hondt para el reparto de escaños da lugar a que en muchas de las circunscripciones el resultado de la elección adopte perfiles claramente mayoritarios: hay 30 distritos en los que se reparten cinco o menos de cinco escaños (cuando la fórmula D'Hondt sólo comienza a generar efectos proporcionales a partir de una magnitud de 7 escaños), en los que se concentra el $25 \%$ de la población y el $33 \%$ de los escaños del Congreso de los Diputados $^{8}$. En 27 de ellos sólo dos partidos logran representación, resultando las demás formaciones totalmente penalizadas. En el resto de distritos, en los que una magnitud mayor da lugar a cotas más altas de proporcionalidad, hay terceros e incluso cuartos partidos que logran representación. Además, en algunas circunscripciones encontraremos, junto a los dos principales partidos de ámbito estatal, partidos nacionalistas o regionalistas que compiten con éxito con los estatales, desplazándoles, incluso, de las primeras posiciones en esos distritos en los que los regionalistas concentran todos sus apoyos electorales ${ }^{9}$. En estas arenas electorales específicas o excéntricas la competición electoral adopta perfiles propios, implicando a terceros y cuartos partidos en la contienda efectiva por la representación. Pese a la variedad de relaciones de proporcionalidad que se dan en los diversos tipos de distritos en función de estas circunstancias, los sesgos desproporcionales siguen ciertas pautas comunes, que se recogen en el cuadro 1: hay partidos que suelen resultar reiteradamente sobrerrepresentados en la operación de transformar votos en escaños, mientras que otros, las terceras y sucesivas fuerzas que encuentran distribuidos sus apoyos por todo el territorio estatal, son sistemáticamente penalizados. Los partidos regionalistas suelen conseguir unos porcentajes de representación bastante proporcionales a los votos que reciben. Desde

\footnotetext{
8 Estas cifras corresponden a la elección del año 2000, aunque fueron similares en anteriores procesos.

9 Nos hemos ocupado de esta peculiaridad del sistema de partidos español, cuantificándola para las elecciones generales, en Oñate y Ocaña (1999: 97 ss.; 2000: 320 ss., y 2005).
} 
las elecciones de 1977 hay ciertas constantes que, a buen seguro, han sido percibidas por los electores ${ }^{10}$ y que pueden ser la base para que adapten su comportamiento en las urnas a los sesgos que conocen se derivan del sistema electoral.

CUADRO 1

Primas y penalizaciones a los partidos en elecciones generales

\begin{tabular}{|c|c|c|c|c|c|c|c|c|c|}
\hline & 1977 & 1979 & 1982 & 1986 & 1989 & 1993 & 1996 & 2000 & Media \\
\hline PSOE & 1,07 & 1,13 & 1,19 & 1,18 & 1,25 & 1,17 & 1,07 & 0,80 & 1,11 \\
\hline AP/PP & 0,55 & 0,43 & 1,15 & 1,14 & 1,18 & 1,16 & 1,16 & 1,53 & 1,04 \\
\hline UCD & 1,30 & 1,37 & 0,48 & & & & & & 1,05 \\
\hline CDS & & & 0,21 & 0,59 & 0,50 & 0,00 & & & 0,32 \\
\hline PCE/IU & 0,57 & 0,62 & 0,28 & 0,44 & 0,54 & 0,53 & 0,57 & 0,42 & 0,50 \\
\hline $\mathrm{CiU}$ & 1,11 & 0,88 & 0,92 & 1,00 & 1,00 & 0,98 & 1,00 & 1,02 & 0,99 \\
\hline PNV & 1,35 & 1,33 & 1,21 & 1,06 & 1,08 & 1,17 & 1,08 & 1,33 & 1,20 \\
\hline $\mathrm{HB}$ & & 1,00 & 0,60 & 1,27 & 1,00 & 0,67 & 0,86 & & 0,90 \\
\hline ERC & 0,50 & 0,43 & 0,43 & & & 0,38 & 0,43 & 0,36 & 0,42 \\
\hline $\mathrm{EE}$ & 1,00 & 0,60 & 0,60 & 1,20 & 1,20 & & & & 0,92 \\
\hline $\mathrm{CC}$ & & & & & & 1,22 & 1,22 & 1,04 & 1,16 \\
\hline BNG & & & & & & & 0,67 & 0,66 & 0,66 \\
\hline EA & & & & & 0,86 & 0,50 & 0,60 & 0,71 & 0,67 \\
\hline UV & & & & 1,00 & 0,86 & 0,60 & 0,75 & 0,00 & 0,64 \\
\hline ChA & & & & & & & & 0,95 & 0,95 \\
\hline
\end{tabular}

FUENTE: Oñate (2002).

Como se dijo más arriba, una primera forma de medir la presencia de la utilización estratégica del voto consiste en atender a las consecuencias que provoca en la fragmentación del respectivo sistema o subsistema de partidos. Para ello habrán de compararse los valores del índice del número efectivo de partidos (Taagepera y Shugart, 1989: 77 ss.) correspondientes a distritos agregados en atención a su tamaño ${ }^{11}$. La hipótesis que trataremos de

\footnotetext{
10 Estas percepciones se basan en la experiencia electoral de los votantes, que se ve reforzada por los sondeos preelectorales las interpretaciones que los medios de comunicación realizan durante las campañas electorales, así como por los mensajes que los partidos lanzan (en el sentido de llamar a una utilización estratégica del voto) durante las mismas, en mayor medida en esos distritos pequeños donde más incidencia pueden tener.

11 Como es sabido, este índice pone de manifiesto la medida en la que el poder político está disperso o concentrado. Tienen dos versiones, electoral y parlamentaria, según se tomen para hacer los cálculos los porcentajes de voto o de escaños de cada partido. La versión que nos interesará, por motivos obvios al estudiar la incidencia del voto estratégico, será la electoral. Para las fórmulas utilizadas para calcular estos índices, sus características y aplicación al caso español, ver Oñate y Ocaña (1999: 36 ss.).
} 
comprobar, como evidencia de la presencia de voto estratégico en las circunscripciones pequeñas (a diferencia de lo que ocurre en las grandes), es que el valor de esos índices será más reducido en los distritos pequeños que en los grandes ${ }^{12}$.

Si agrupamos los diversos distritos de las elecciones generales en cinco tipos, en atención a su tamaño, se comprueba — como se aprecia en el cuadro 2-que el índice del número efectivo de partidos correspondiente —como promedio para las elecciones de 1977 a 1996 - a cada uno de ellos crece progresivamente a medida que pasamos de un tipo de distrito a otro de tamaño superior ${ }^{13}$, lo que bien puede interpretarse como la manifestación de una mayor utilización del voto estratégico o sofisticado en esos distritos pequeños. En el cuadro 2 se han separado los datos correspondientes a la elección de 2000 porque introducían una considerable desviación típica respecto del promedio de los ocho procesos en los distritos de menor tamaño. La explicación de ese valor más elevado del índice del número efectivo de partidos en los distritos tipo I en la última convocatoria viene dada por la incursión en Ceuta y Melilla (los dos casos de distrito con tamaño igual a 1) de dos nuevos partidos que compitieron con éxito con los dos principales, y desde presupuestos que implicaban el rechazo de las pautas partidistas tradicionales: el Grupo Independiente Liberal (GIL) en Ceuta y el Bloque Localista de Melilla consiguieron romper el bipartidismo que tradicionalmente imperaba en esos distritos uninominales, logrando hacerse con el 18 y el $25 \%$ del voto, respectivamente. Los especiales avatares que han caracterizado a la vida política ceutí y melillense en los dos últimos años hacen que los valores relativos al número efectivo de partidos correspondientes a la convocatoria de 2000 deban ser observados con cautela: su incremento parece responder más al descontento de buena parte de su electorado con los partidos tradicionales que a la fidelidad a los postulados de un partido minoritario - y pese a que darle el voto pudiera implicar «desperdiciarlo»- Poniendo entre paréntesis los datos relativos a los dos casos de distritos uninominales, sí puede apreciarse que en los distritos pequeños (de cinco o menos de cinco escaños) el número efectivo de partidos es menor en cinco décimas que en los medianos y grandes. Las 28 circunscripciones (dejando aparte las de Ceuta y Melilla) que se incluyen en este grupo de distritos pequeños registran una competición limitada, en la práctica, a los dos principales partidos.

12 Como se ha dicho con anterioridad, la agregación aleatoria desde el punto de vista de las variables geográfica y de tendencia política mayoritaria, así como la presencia significativa de plurales partidos de ámbito no estatal en muchos de esos distritos, conducen a que la explicación de eventuales diferencias en cuanto a la fragmentación entre distritos pequeños y grandes deba ser realizada atendiendo a la variable institucional de la magnitud del distrito y de la mayor utilización del voto estratégico en los pequeños, propiciando que los partidos de menor entidad tengan más porcentaje de apoyo en las urnas en los distritos grandes que en los que no lo son, dando lugar en aquéllos a sistemas de partidos con índices de número efectivo de partidos más altos.

\footnotetext{
13 Las desviaciones típicas correspondientes a cada distrito y a cada convocatoria son, prácticamente, irrelevantes.
} 
CUADRO 2

Número efectivo de partidos en elecciones generales según tamaño de distrito*

\begin{tabular}{llllllr} 
& \multicolumn{4}{c}{} & \multicolumn{3}{c}{ Tipos de distrito } \\
\cline { 2 - 5 } & I & II & III & IV & V & España \\
\hline $1977-1996$ & 2,71 & 3,11 & 3,35 & 3,38 & 3,72 & 3,21 \\
2000 & 2,78 & 2,44 & 2,92 & 2,72 & 3,13 & 3,03
\end{tabular}

* Tamaños de distrito: tipo I: 1 escaño; tipo II: de 3 a 5 escaños; tipo III: de 6 a 8 escaños; tipo IV: de 9 a 16 escaños; tipo V: más de 30 escaños.

FUENTE: Actualizado para 2000 de Oñate y Ocaña (1999: 82).

Esos distintos valores tendrían una explicación evidente si se tratara de la versión parlamentaria del índice, dados los severos sesgos desproporcionales (efectos mecánicos) que se derivan del sistema electoral español en los distritos pequeños, en los que sólo los grandes partidos logran representación. La lógica es de otro tipo cuando se trata de la versión electoral del índice: hemos de suponer que el comportamiento electoral de los votantes es previo a la generación de dichos sesgos desproporcionales; así las variaciones entre los valores del índice del número efectivo de partidos deben ser, en principio, explicadas por la utilización estratégica del voto que se hace en los de menor tamaño. Los ciudadanos optan en menor medida por formaciones pequeñas, que sospechan o intuyen no tienen muchas posibilidades de obtener representación; prefieren votar más por los partidos grandes, reduciéndose, de esta forma, la fragmentación —el número efectivo de partidos— resultante. Estas afirmaciones deberán ser matizadas, no obstante, al tener en cuenta las diferencias que se observan en lo manifestado por los electores españoles entrevistados para los estudios preelectorales (agregando sus respuestas según el tamaño del distrito) en cuanto a su cercanía a los partidos minoritarios, como veremos ocurre con IU. La tendencia a explicar la diferencia del valor del índice del número efectivo de partidos atendiendo al tamaño del distrito (a la utilización del voto estratégico) deberá ser tomada, por tanto, con las debidas cautelas.

La segunda forma de comprobar la presencia de voto estratégico en las elecciones generales españolas requiere la utilización de encuestas postelectorales ${ }^{14}$, que permiten comparar los

\footnotetext{
14 Usaremos los datos de los Estudios postelectorales del Centro de Investigaciones Sociológicas números 1327, 1542, 1543, 1842, 2061, 2210 y 2384. Debe tenerse en cuenta el posible sesgo introducido por la utilización de estudios de carácter postelectoral: puede haber simpatizantes de IU que han decidido votar por el PSOE y racionalizan ex post, a los pocos días de haber votado estratégicamente, sus respuestas en cuanto a simpatía y ubicación ideológica para hacerlas coherentes con su opción electoral.
} 
porcentajes de votantes que, en los distritos pequeños y grandes, habiendo dicho sentirse cercanos de un partido minoritario o ubicándose en posiciones ideológicas similares a las que ocupa esta formación, han acabado confiriéndole su voto. Gunther afirmaba, a partir de datos de las elecciones de 1979 y 1982, que los partidarios de las pequeñas formaciones les votaban menos en los distritos pequeños que en los grandes, entendiendo que este fenómeno se debía a la intuición de los electores de los distritos pequeños respecto de las escasas posibilidades reales de esos partidos de lograr representación. Debido a dificultades para obtener datos fiables relativos a las distintas formaciones pequeñas que presentan candidatos en cada distrito, deberemos conformarnos con analizar el caso de IU, ya que es el único partido pequeño relevante que presenta candidaturas en todos los distritos del Estado ${ }^{15}$.

No obstante, como se señalaba anteriormente, es necesario pensar en la posibilidad de que en la elección de 1979 no se diera uno de los presupuestos básicos para que exista voto estratégico: el de que los electores cuenten con la suficiente experiencia electoral como para estar en condiciones de intuir, basándose en el conocimiento de las consecuencias de la aplicación del sistema electoral en los distritos pequeños, la infrarrepresentación que sufrirán las formaciones pequeñas. Parece poco razonable —como aducía Cox (1997: 116) - pensar que los electores, aun los más avezados, estén en condiciones de anticipar los complejos cálculos que la aplicación de la fórmula D’Hondt implica, para poder predecir qué formaciones ocuparán las posiciones de primer y segundo perdedor al atribuirse el último escaño del distrito. Sería más sensato pensar que Gunther se refería —al hablar de los electores españoles - a una vaga intuición, basada en la experiencia, en los sondeos preelectorales, así como en las llamadas al voto útil hechas por los candidatos del partido eventualmente beneficiado por esa utilización estratégica del voto, relativa a las consecuencias derivadas para las pequeñas formaciones del efecto reductor del sistema electoral en los distritos de reducida magnitud ${ }^{16}$. Todo ello hace que los electores no estén obligados a realizar sesudos cálculos para anticipar si su voto puede tener especial incidencia o no en la elección, bien en la victoria (o si lo es por mayoría absoluta), bien en que la pequeña formación pueda lograr un escaño, es decir, acerca de lo decisivo que pueda ser su voto, según el tamaño del distrito en que vaya a votar. Partiendo de la validez de esta inter-

\footnotetext{
15 Podemos agregar las respuestas de los distintos distritos pequeños y grandes respecto de la proximidad a esta formación, la ubicación del entrevistado en posiciones cercanas a las que ocupa esta formación y el voto que finalmente se le confiere, así como comparar los resultados para los diversos casos agregados en el conjunto del territorio del Estado.

16 Parece claro que los electores estiman lo reñido de la competición electoral en función de los sondeos que aparecen durante el período electoral en los medios de comunicación, así como de las reflexiones e interpretaciones que los informadores, comentaristas y candidatos de esos distritos pequeños realizan a partir de las encuestas preelectorales. De manera similar, a lo largo de la precampaña o en la misma campaña es frecuente que en los medios se hagan comentarios generales acerca del sistema electoral, sobre sus características y consecuencias, que se ven enriquecidos (reforzados en sus efectos) por la experiencia democrática del país —y que además son reiterados durante las campañas de las diferentes formaciones políticas, según les resulte o no conveniente-.
} 
pretación, la utilización de los datos correspondientes a la elección de 1979 parece poco recomendable, dada la poca experiencia con la que contaban entonces los votantes españoles, limitada a un solo proceso electoral que, además, tenía carácter fundacional, como la gran cantidad de candidaturas que se presentaron puso de manifiesto.

De los datos que se han recogido en el cuadro 3 se desprenden conclusiones distintas de las propuestas por Gunther. Efectivamente, el porcentaje de voto a IU es menor en los distritos pequeños que en los grandes, pero ello parece ser el fiel reflejo de una proximidad al partido también menor en este tipo de distrito. Sólo en las elecciones de 1979 y 1982, las estudiadas por Gunther, parece haber una excesiva desproporción entre la diferencia en voto de la formación en distritos pequeños y grandes y el grado de proximidad hacia ella en cada tipo de distrito, siendo la diferencia en voto mucho mayor, en términos relativos, que la diferencia en proximidad ${ }^{17}$. Pero para el resto de convocatorias parece haber una relación clara entre la diferencia en el grado de proximidad y la diferencia en voto entre distritos pequeños y grandes, relación que impiden hablar con suficiente certeza de uso estratégico del voto, al menos de forma significativa.

CUADRO 3

Proximidad y voto a PCE/IU en elecciones generales, 1982-2000*

\begin{tabular}{rrrrrrr}
$\begin{array}{r}\text { Ubicación } \\
\text { en distritos } \\
\text { pequeños }\end{array}$ & $\begin{array}{r}\text { Ubicación } \\
\text { en distritos } \\
\text { grandes }\end{array}$ & $\begin{array}{r}\text { Cercanía } \\
\text { en distritos } \\
\text { pequeños }\end{array}$ & $\begin{array}{r}\text { Cercanía } \\
\text { en distritos } \\
\text { grandes }\end{array}$ & $\begin{array}{r}\text { Voto } \\
\text { en distritos } \\
\text { pequeños }\end{array}$ & $\begin{array}{r}\text { Voto } \\
\text { en distritos } \\
\text { grandes }\end{array}$ \\
\hline 1982 & 11,0 & 11,3 & - & - & 1,5 & 3,0 \\
1986 & 21,5 & 26,9 & 7,3 & 8,8 & 1,7 & 4,0 \\
1989 & 18,2 & 27,8 & 11,2 & 19,0 & 7,6 & 11,0 \\
1993 & 20,5 & 24,6 & 18,4 & 21,7 & 8,2 & 9,4 \\
1996 & 19,1 & 25,5 & - & - & 7,7 & 10,9 \\
2000 & 16,2 & 18,7 & 7,5 & 9,1 & 4,3 & 5,5
\end{tabular}

* Se considera distritos grandes a aquellos en los que se reparten más de 5 escaños. «Ubicación» se refiere al porcentaje de entrevistados que se sitúan en la escala ideológica en posiciones similares a las que ocupa el PCE/IU (1, 2 y 3). «Cercanía» alude al porcentaje de entrevistados que dicen simpatizar o sentirse cercanos a esta formación. «Voto» se refiere al porcentaje de ciudadanos que dicen haber optado por la formación en la elección inmediatamente anterior.

FuENTE: Estudios postelectorales del CIS números 1327, 1543, 1842, 2061, 2210 y 2384.

\footnotetext{
17 No obstante, tratándose de unos porcentajes tan reducidos — que implican tan pocos casos en el sondeo—, es arriesgado formular conclusiones de general aplicación. A esas limitaciones se suma que el cuestionario del estudio postelectoral de 1982 no recoge la pregunta relativa a cercanía a los partidos (como ocurre con el de 1996). Por ello se acude también, de forma complementaria, a la ubicación ideológica, siendo conscientes de que buena parte de quienes se ubican en la posición 3 pueden ser votantes del PSOE. También habrá de tenerse en cuenta la diferencia entre el voto manifestado y el voto real de IU en cada elección, que fue de 4,0,4,7, 9,1, 9,6, 10,5 y 5,5\%, respectivamente, para cada uno de los procesos electorales desde 1982 y para el conjunto del territorio.
} 
Por todo ello conviene atender, de forma complementaria, a la tercera propuesta metodológica formulada para detectar la presencia de voto estratégico, basada en la comparación de los valores que alcanza el índice SF en cada distrito. Parece razonable pensar que el fenómeno del voto estratégico tenderá a desaparecer en las elecciones españolas a medida que aumente la magnitud del distrito, fundamentalmente cuando se supere el umbral a partir del cual la fórmula electoral comienza a generar efectos proporcionales (por encima de los seis escaños). Cox (1997: 112) comprobó que el fenómeno del voto estratégico desaparecía en cuanto la magnitud del distrito aumentaba por encima de cinco escaños. No obstante, estudió el caso español limitando su análisis a tres procesos electorales (los de 1982, 1986 y 1989) caracterizados por dar lugar a sendas mayorías absolutas del partido ganador (configurando un sistema de partido predominante) con una oposición poco homogénea, dividida y ausente en la práctica. Esta limitación pudo haber condicionado severamente los resultados de sus observaciones, dadas las peculiaridades coyunturales de los procesos elegidos. Al no haber apenas competitividad entre los dos primeros partidos políticos, hay menos motivos para que el voto a la tercera y sucesivas fuerzas sea reducido estratégicamente. Los electores pueden percibir que hay menos en juego y que su voto tendrá consecuencias menos importantes, al influir en menor medida en el resultado final de la elección ${ }^{18}$. Para tratar de comprobarlo, hemos calculado el índice SF para los distritos de tres, cinco y siete escaños en un número mayor de procesos electorales (los celebrados entre 1982 y 2000) y que no estén sujetos a los condicionantes coyunturales mencionados de los que adolecían los considerados por Cox en su análisis (gráfico 1).

Como se aprecia en el gráfico 1, a medida que aumenta el tamaño del distrito, se reduce la probabilidad de voto estratégico, en tanto que los valores del índice SF se aproximan al 1 y se alejan del valor 0 . En el grupo de los distritos con magnitud 7 no se observa ni un solo caso cuyo índice SF haya registrado valor por debajo de 0,5 a lo largo de los seis procesos electorales. En la gran mayoría de esos distritos se registra un valor de índice SF cercano al 1, lo que excluye la utilización del voto estratégico. En los distritos grandes no se dan las situaciones que Cox califica como de equilibrio duvergeriano, en las que sólo dos partidos compiten efectivamente por la representación. Se comprueba, por tanto, que el fenómeno del voto estratégico es exclusivo de los distritos de menor tamaño, en los que se dan los presupuestos para su existencia, desapareciendo de aquellos en los que el sistema electoral genera efectos relativamente proporcionales y confiere representación a los pequeños partidos ${ }^{19}$.

18 Esto ya fue detectado para el caso del Partido Liberal británico por B. E. Cain, «Strategic Voting in Britain», American Journal of Political Sciece, 22, 1978 (639-655), cit. en Blais y Carty (1991: 81): «el voto liberal en Gran Bretaña es menor en los distritos en los que hay una competición reñida entre los dos principales partidos: dada la mayor posibilidad de influir en el resultado global de la elección, hay más liberales que desertan de su partido».

19 No obstante, hay casos en los que incluso en los distritos pequeños la distribución de valores del índice SF se acerca al vaIor 1. Esos casos pueden explicarse por la no utilización del voto estratégico (dándose un voto no instrumental: el de ciudada- 
GRÁFICO 1

Índice SF según tamaño de distrito (en porcentajes respectivos), 1982-2000

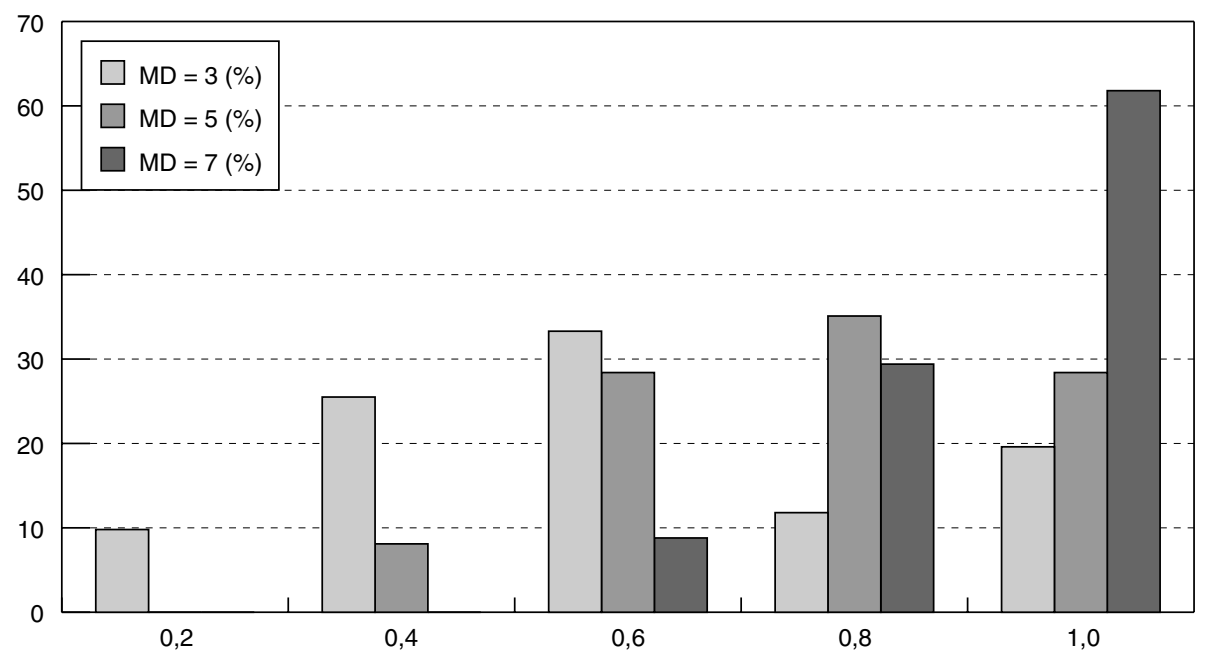

Dado que el número de casos de cada tipo es distinto, se presenta el porcentaje de casos respecto del número total de distritos que tengan ese tamaño.

Antes de analizar las distribuciones de los valores del índice SF, debe recordarse que cuando Cox trató de aplicar su análisis al caso de las elecciones generales españolas de 1982, 1986 y 1989 se encontró con la dificultad de que había un gran número de distritos pequeños en los que el cociente de la segunda candidatura perdedora al atribuirse el último escaño correspondía a una lista que había logrado representación en ese distrito en la misma elección. En este sentido, afirmaba Cox: (1997: 116 y 117): «la lista que tiene el segundo cociente perdedor consiguió escaños en todos los distritos excepto en 6 de ellos, en la elección de 1986 (...). Hay muy pocos casos (21 [de los 156 casos-distritos en los tres procesos]) en los que el segundo cociente perdedor correspondiera a un partido que no hubiera logrado representación». Este hecho implicaba que la competitividad entre el segundo perdedor y el primero era elevada, por lo que la incertidumbre acerca de la atribución de ese último escaño era alta. En esa tesitura no resulta fácil para el elector anticipar qué partido obtendrá el último escaño, ni para las encuestas de los sondeos preelectorales pronosticar con suficiente fiabilidad cuál de los partidos acabará consiguiéndolo. Por moti-

nos que votan al pequeño partido pese a saber que no logrará representación) y por la presencia de partidos de ámbito no estatal que compiten con los dos principales de ámbito estatal en determinados distritos, elevando el número de partidos que efectivamente compiten por la representación en ellos a tres o, incluso, a cuatro. 
vos obvios, tampoco en este caso la historia electoral del distrito sirve de mucho para hacer algún pronóstico mínimamente fiable. La mayor incertidumbre acerca de la atribución de ese último escaño disminuye — si no elimina - la probabilidad del comportamiento estratégico, al no darse los presupuestos que su existencia demanda ${ }^{20}$.

No obstante, según nuestros cálculos, las candidaturas que teniendo el segundo cociente perdedor al repartirse el último escaño han logrado algún otro de los repartidos en ese mismo distrito no son tantas como Cox calculaba ${ }^{21}$. Como se observa en el cuadro 4 , la cantidad de distritos en los que se dan las condiciones que permiten intuir una presencia significativa de voto estratégico es considerablemente elevada, lo que hace pertinente el análisis de la distribución de los valores respectivos del índice SF.Y, sobre todo, si prestamos atención a los distritos pequeños: sólo en uno de cada cuatro el partido con el segundo cociente perdedor al distribuirse el último escaño logró representación; esto es, en el 75\% de los casos se dieron las condiciones «ideales» para un uso estratégico del voto en parte de los electores.

CUADRO 4

Distritos con segundo perdedor con representación*

\begin{tabular}{|c|c|c|c|c|c|c|}
\hline & 1982 & 1986 & 1989 & 1993 & 1996 & 2000 \\
\hline \multicolumn{7}{|l|}{$\mathrm{n}$} \\
\hline $\mathrm{MD}</=5$ & $13 / 30$ & $15 / 31$ & $5 / 31$ & $3 / 30$ & $4 / 30$ & $6 / 30$ \\
\hline$M D>5$ & $12 / 22$ & $12 / 21$ & $20 / 21$ & $18 / 22$ & $19 / 22$ & $16 / 22$ \\
\hline Total & $25 / 52$ & $27 / 52$ & $25 / 52$ & $21 / 52$ & $23 / 52$ & $22 / 52$ \\
\hline \multicolumn{7}{|l|}{ Porcentaje } \\
\hline $\mathrm{MD}</=5$ & 43,3 & 48,4 & 16,1 & 10,0 & 13,3 & 20,0 \\
\hline$M D>5$ & 54,5 & 57,1 & 95,2 & 81,8 & 86,4 & 72,7 \\
\hline Total & 48,1 & 51,9 & 48,1 & 40,4 & 44,2 & 42,3 \\
\hline
\end{tabular}

* En $\mathrm{n}$ y en porcentaje sobre $\mathrm{N}$ respectivo.

$\mathrm{MD}</=5$ : distritos con magnitud o tamaño menor o igual a 5 .

$\mathrm{MD}>5$ : distritos con magnitud o tamaño superior a 5.

20 El presupuesto de la existencia del voto estratégico es una situación en la que el elector puede anticipar con suficiente fiabilidad que su partido preferido (pequeño) no logrará representación. En esa anticipación pueden influir tanto las encuestas preelectorales como la historia electoral del distrito y los mensajes de campaña de los partidos políticos y sus candidatos (en la medida en la que, como es habitual, no haya cambios significativos en las etiquetas de los principales partidos y la volatilidad sea baja). Sobre la influencia que pueden tener los efectos de las campañas electorales en los electores puede verse nuestro trabajo en Anduiza y Oñate (2004), así como Crespo, Martínez y Oñate (2004).

21 Cox calculaba que había 135 casos-distritos (de los 156 considerados, en las elecciones de 1982 a 1989) en los que la candidatura con segundo cociente perdedor al atribuirse el último escaño había logrado otro de los repartidos en ese mismo distrito, siendo sólo 21 aquellos en los que no se daba esta doble circunstancia. Según nuestros cálculos, como se aprecia en el cuadro 4, el número de distritos en los que se da esa doble condición es, para los distritos pequeños en las elecciones de 1982 a 1989, de 77, ascendiendo a 79 el número de distritos que no la cumplían. 
Pero para tratar de precisar más la eventual presencia de condiciones idóneas para la utilización estratégica del voto podemos dividir los seis procesos electorales considerados en dos grupos, atendiendo a la previsibilidad del resultado respectivo (cuadro 5). En las elecciones correspondientes a la década de los años ochenta — que Cox estudió- se registraron sucesivas mayorías absolutas, sin que hubiera dos partidos claramente competitivos: anticipar qué partidos ocuparían la segunda y la tercera posición —los puestos de primer y segundo perdedor - al repartirse el último escaño era mucho menos fácil, circunstancias que no se dieron en los procesos de los años noventa (elecciones de 1993, 1996 y 2000). En el cuadro 5 se observa cómo en las elecciones celebradas durante esta década las condiciones para el voto estratégico en los distritos pequeños fueron mucho más propicias (en el $85 \%$ de los distritos pequeños el partido con el segundo cociente perdedor no logró representación). Cuando hay una elevada competitividad entre los dos primeros partidos por conseguir la victoria en la elección (o por ganar por mayoría absoluta, como fue el caso en 1989), los electores tenderán en mayor medida a hacer una utilización estratégica de su voto, como hemos visto que ocurre en otros países.

\section{CUADRO 5}

Distritos con segundo perdedor con representación en los años ochenta y noventa*

\begin{tabular}{lrrr} 
& $1982+1986+1989$ & $1993+1996+2000$ & $1982-2000$ \\
\hline $\mathrm{n}$ & & & $46 / 182$ \\
$\mathrm{MD}</=5$ & $33 / 92$ & $44 / 64$ & $97 / 130$ \\
$\mathrm{MD}>5$ & $44 / 64$ & $53 / 66$ & $143 / 312$ \\
\hline Total & $77 / 156$ & $66 / 156$ & 25,3 \\
Porcentaje & & & 74,6 \\
MD $</=5$ & 35,9 & 68,8 & 40,3 \\
MD $>5$ & 68,8 & 80,3 & 45,8 \\
\hline Total & 49,4 & 42,3 &
\end{tabular}

* En $\mathrm{n}$ y en porcentaje sobre $\mathrm{N}$ respectivo.

$\mathrm{MD}</=5$ : distritos con magnitud o tamaño menor o igual a 5.

$\mathrm{MD}>5$ : distritos con magnitud o tamaño superior a 5 .

Al observar el cuadro 5 cobra sentido, por un lado, estudiar la evidencia de la presencia de voto estratégico en España al diluirse las reservas que albergaba Cox en su análisis de 1997; por otro, acotar el tipo de distritos en el que mejores condiciones se dieron para la existencia del voto estratégico: distritos pequeños, y especialmente en las tres elecciones de la década de los años noventa. En las convocatorias de la década de los años ochenta 
cabía anticipar una baja competitividad entre las dos fuerzas más votadas: la incertidumbre acerca del resultado de la elección era baja, por lo que los incentivos para hacer un uso estratégico del voto eran, igualmente, pequeños. En cambio, en las elecciones de 1993 y 1996 la competitividad entre las dos primeras fuerzas era mucho mayor, manteniéndose hasta el último momento las dudas acerca de cuál de las dos conseguiría la victoria. Aunque esa incertidumbre no fue tan alta en las elecciones de 2000 , la competitividad percibida por los ciudadanos antes de la celebración de los comicios fue también considerable, si bien acabó siendo mucho menor ${ }^{22}$. En esas circunstancias el valor de cada sufragio aumentaba, por lo que los partidarios de las pequeñas fuerzas podían sentirse más tentados de hacer un uso estratégico de su voto. Cabe por todo ello anticipar que este voto sofisticado, útil o estratégico fue mayor en las elecciones de 1993, 1996 y 2000.

Si se agregan los 52 distritos de las elecciones generales en atención a que su magnitud sea bien superior o bien inferior o igual a cinco escaños, se observa que las respectivas distribuciones del índice SF en las elecciones celebradas de 1982 a 2000 siguen pautas bien distintas (gráfico 2). Como cabía esperar, la distribución de la agregación de los valores de los índices correspondientes a distritos en los que se reparten más de cinco escaños es de carácter unimodal, con la mayor acumulación de casos en torno al valor 1. No hay ningún caso para ese tamaño de distrito que registre un valor de índice SF por debajo del 0,5 . En este tipo de distrito no existen las condiciones para que los ciudadanos puedan predecir con cierta certeza a quién corresponderá ese último escaño, excluyéndose, por tanto, los presupuestos para la utilización estratégica del voto ${ }^{23}$.

Si se atiende, en cambio, a la distribución que sigue la agregación de los valores del índice SF correspondientes a los distritos pequeños, se aprecia que es de carácter bimodal: hay un número elevado de distritos en los que el índice SF registra valores por debajo del 0,5, manifestando una utilización significativa del voto estratégico. Una parte del electorado percibe o intuye que las terceras fuerzas no tienen opciones reales para lograr (ese último) escaño, por lo que algunos de sus eventuales votantes (instrumentales) optan por no conferirles finalmente su voto, decidiendo hacer una utilización estratégica del mismo: tanto los medios de comunicación —haciéndose eco de los sondeos preelectorales para esos distritos pequeños- como los candidatos del partido que se beneficiaría del voto estratégico di-

\footnotetext{
22 En 1996, un 45,7\% de ciudadanos anticipaba la victoria del PP —-mientras que un 16,3\% consideraba que la elección sería ganada por el PSOE-, mientras que en el año 2000 el porcentaje de ciudadanos que decía creer que ganaría el PP era el 64,2\%, apostando por una victoria del PSOE sólo el 10,0\%: las diferencias eran considerables. Datos de los estudios preelectorales del CIS correspondientes a los comicios de 1996 y 2000 (preguntas 24 y 16).

23 Los efectos reductores del sistema electoral serán menos intensos en este tipo de distritos, grandes, lo que habitualmente es puesto de manifiesto (indirectamente) durante la campaña electoral por los medios de comunicación y por los propios partidos políticos. Acerca de las consecuencias del sistema electoral español, véase Oñate (2004).
} 
GRÁFICO 2

Índice SF según tamaño de distrito (en porcentajes respectivos)

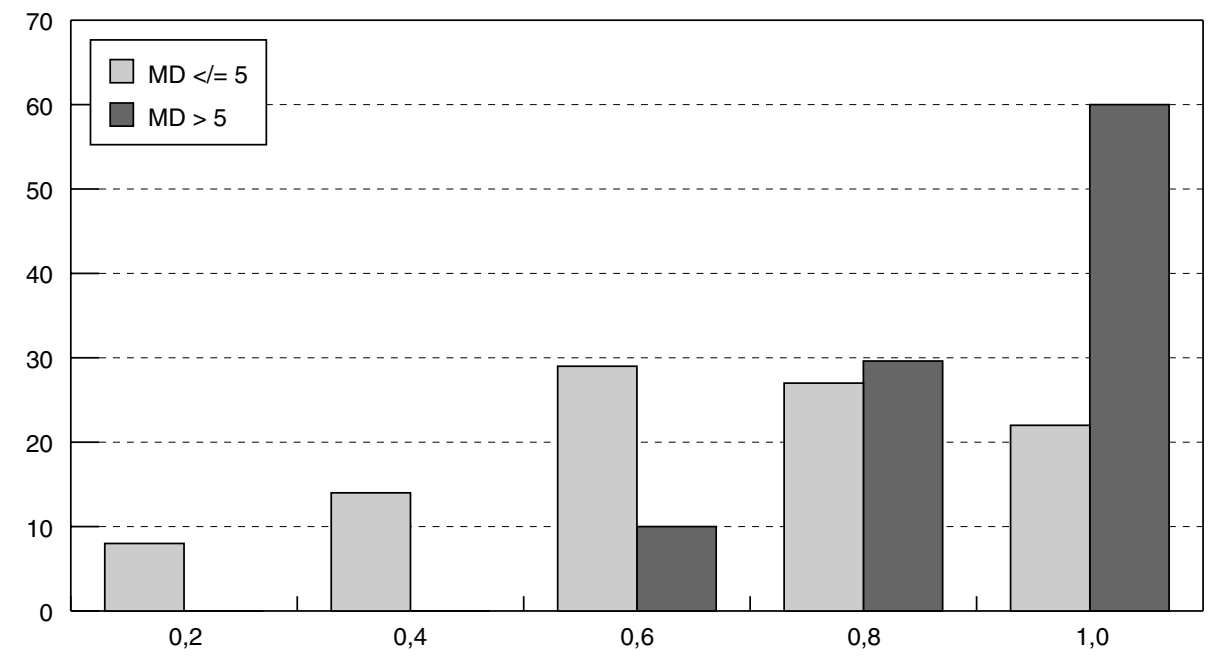

fundirán entre la población las pocas o nulas posibilidades del pequeño partido para hacerse con un escaño en el distrito (y el consiguiente desperdicio que se daría de optar por él en las urnas). No obstante, se registra un buen número de casos que se ubican por encima del valor 0,5 , aproximándose al 1 , lo que indica bien que algunos de esos votantes no dan un sentido instrumental a su voto (sino más bien expresivo ${ }^{24}$ ), bien que para otros electores esos terceros partidos han sido percibidos como competitivos, o bien que el voto no era visto como tan decisivo para la victoria electoral; el resultado ha sido que algunos de los simpatizantes de los pequeños partidos han acabado votando por ellos. Esta distribución es, en principio, coherente con la hipótesis de partida y con las previsiones de Cox (1997: 112). Pero si, a partir de la historia electoral de esos distritos pequeños, así como de la difusión dada a las encuestas preelectorales y los efectos del sistema electoral en esos pequeños distritos hecha en la campaña electoral, los electores saben o intuyen que las terceras fuerzas apenas tienen en ellos posibilidades reales de lograr un escaño (el último repartido), ¿debemos deducir que los votantes de esos terceros partidos son votantes irracionales o no-instrumentales? Cabe que sea ésa, en gran medida, la explicación. No obstante, todavía podemos precisar un poco más nuestro análisis para tratar

24 Dada la forma no instrumental de entender la política de buena parte de los simpatizantes de IU, esta última bien podría ser la causa del carácter bimodal de la distribución a que se hace referencia. 
de comprender el motivo de la alta presencia de voto no-instrumental en estos distritos pequeños.

Como decíamos más arriba, Cox limitó su análisis a los procesos electorales de la década de los años ochenta. Pero en ellos se dieron unas características peculiares que bien podrían haber condicionado el comportamiento de los electores: se trataba de elecciones cuyo resultado era fácilmente predecible por los ciudadanos. Como hemos anticipado, un partido consiguió sistemáticamente la mayoría absoluta de escaños del Congreso de los Diputados, quedando el segundo partido a considerable distancia. Éste no consiguió mejorar sustancialmente sus resultados en ninguno de los procesos de la década, mientras que las terceras fuerzas, PCE/IU y CDS, incrementaban progresivamente sus resultados. Por otro lado, en los tres procesos electorales de la década se registraron en la fisonomía de la oposición cambios notables que dificultaron que su configuración fuera previsible para los electores antes de cada proceso: colapso de la UCD (que en las elecciones de 1982 sólo logró un 7\% del voto y 11 escaños y desapareció en la siguiente convocatoria); progresivo incremento del voto del CDS (que paso de un 3\% del voto y dos actas de diputado en 1982 a tener 16 escaños en 1986 y 19 en 1989); presencia también cada vez mayor del PCE/IU (que pasó de 23 escaños en 1979 a tener cuatro en 1982, siete en 1986 y 17 en 1989); y muy variados resultados de los partidos de ámbito no estatal, en cuyas filas se integró buena parte de la elite regional de la UCD cuando esta formación se desintegró, partidos que compitieron con éxito en muchos distritos con los partidos de ámbito estatal, haciendo más complejas las respectivas pautas de competición electoral. En las elecciones generales celebradas en la década de los años noventa, la victoria - y su grado - fue mucho menos predecible para los electores (algo más en el año 2000, aunque no en la medida en la que efectivamente se produjo) y el futuro de los otros partidos de la oposición (tercero y sucesivos) se aclaró considerablemente, desapareciendo los centristas y consolidándose, generalmente, el apoyo (creciente) de la coalición IU, así como de muchas de las fuerzas de ámbito no estatal. Al aumentar la competitividad entre los dos primeros partidos, el voto de cada ciudadano contaba más. Los resultados de los comicios de 2000 se alejaron de estas características, aunque no fueron fácilmente predecibles para la mayoría de los electores ${ }^{25}$.

Partiendo de estas consideraciones, puede resultar útil distinguir, a efectos analíticos, entre los valores que el índice SF alcanzó en los procesos electorales celebrados en los años ochenta y en los correspondientes a los años noventa, partiendo de la hipótesis de que en éstos hubo más utilización estratégica del voto que en los comicios de los años ochenta, ya

\footnotetext{
25 Parte de los ex votantes de IU bien podrían haber dado en esta convocatoria de 2000 su voto al PSOE por temer una mayoría absoluta del PP, por entender que el pacto preelectoral PSOE-IU les incitaba a ese tránsito, y por mucho que el PSOE se abstuviera en esta ocasión —en virtud del pacto- de hacer una llamada explícita al voto útil, o bien porque la deriva de IU en los últimos años les alejaba de la misma.
} 
que los resultados de éstos eran más predecibles: se conocía el partido que ganaría las elecciones (sabiéndose que lo más probable era que lo hiciera por mayoría absoluta de escaños), el primer partido de la oposición no suponía una amenaza a la preeminencia del partido gobernante, y el voto de los partidarios de las terceras fuerzas tenía menos influencia general. La consecuencia fue, a efectos de este análisis, que el voto de los partidarios de terceras fuerzas condicionaba menos el resultado general, por lo que podían anticipar que su voto no haría ganar o perder a un partido, pudiendo sentirse más tranquilos al conferir su voto a la tercera o cuarta fuerza política y ejercer su voto de manera menos instrumental ${ }^{26}$.

GRÁFICO 3

Índice SF en distritos pequeños (según previsibilidad de resultados, en porcentajes respectivos)

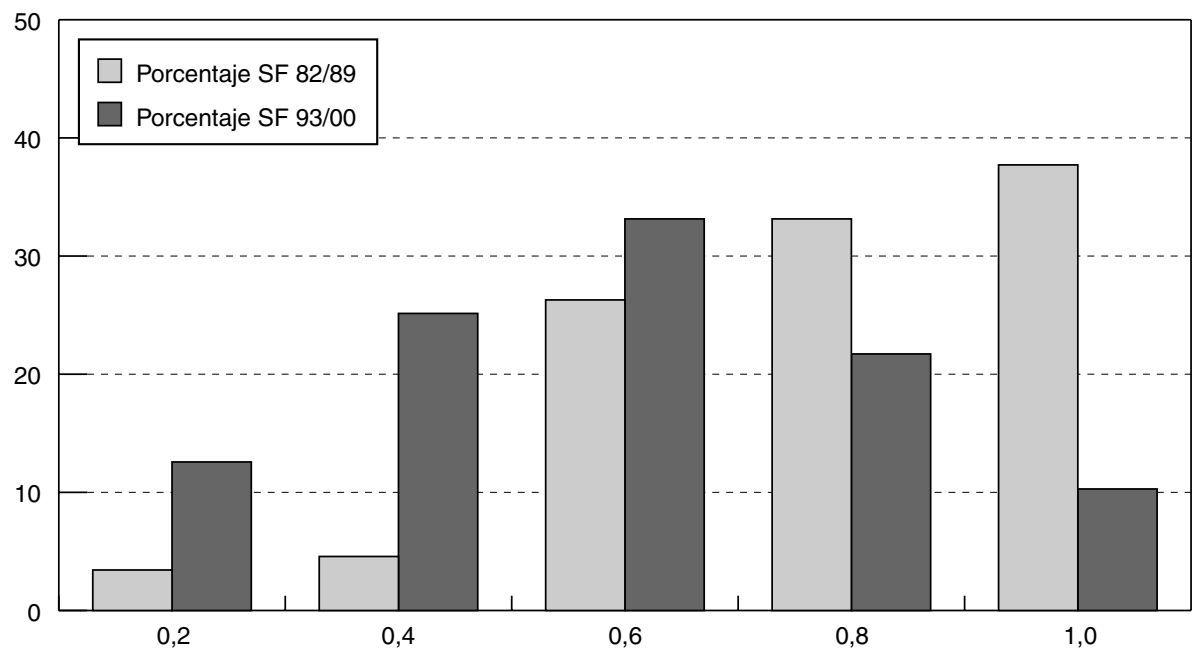

Los datos que se recogen en el gráfico 3 confirman básicamente la última hipótesis planteada. En las elecciones de 1993, 1996 y 2000 hubo más utilización estratégica del voto que en las de 1982, 1986 y 1989: en tanto la competitividad percibida -ex anteentre las dos fuerzas políticas era en 1993, 1996 y 2000 evidentemente mayor y, por tanto, el voto de cada elector podía ser percibido como más decisivo, se daban las condiciones para que un número considerable de partidarios de los terceros y sucesivos

26 El voto a IU en la elección de 1989 sí tenía importancia por poder implicar la pérdida de la mayoría absoluta para el PSOE, pero la cercanía a la coyuntura que culminó con la huelga general de 14 de diciembre de 1988 disminuyó, probablemente, la utilización estratégica del voto, incrementando el carácter expresivo o no-instrumental del mismo. Además, se tenía la certeza de que el PSOE no perdería la elección a favor del PP. 
partidos decidieran dar su voto a su segunda opción (second best), que sí contaba con posibilidades reales de ganar escaños, desertando de su primera opción. La distribución de los valores del índice SF en las elecciones del primer período de los señalados (elecciones de 1982, 1986 y 1989) es de carácter unimodal, con tendencia a la acumulación en torno al valor 1: el cociente del segundo partido perdedor al repartirse el último escaño en cada distrito quedó considerablemente cerca del cociente correspondiente al primer perdedor.

Por el contrario, la distribución del índice SF en las elecciones del segundo período señalado $(1993,1996$ y 2000) es de carácter bimodal, con más valores cercanos al 0: hubo más ocasiones en las que se dio un equilibrio duvergeriano. No obstante, en estos comicios se registró un buen número de casos en los que los votantes decidieron conceder su voto a terceras fuerzas, tanto de ámbito estatal como de carácter regional. Sin duda, la pluralidad de arenas electorales, en las que más de dos partidos compiten efectivamente por la representación, así como la presencia de votantes no instrumentales entre el electorado de IU, influyeron en esos valores del índice SF. Estas diferentes pautas de las elecciones de una y otra década se aprecian con mayor facilidad observando la distribución que experimenta el índice SF en cada uno de los procesos electorales, tal y como se recoge en el gráfico 4.

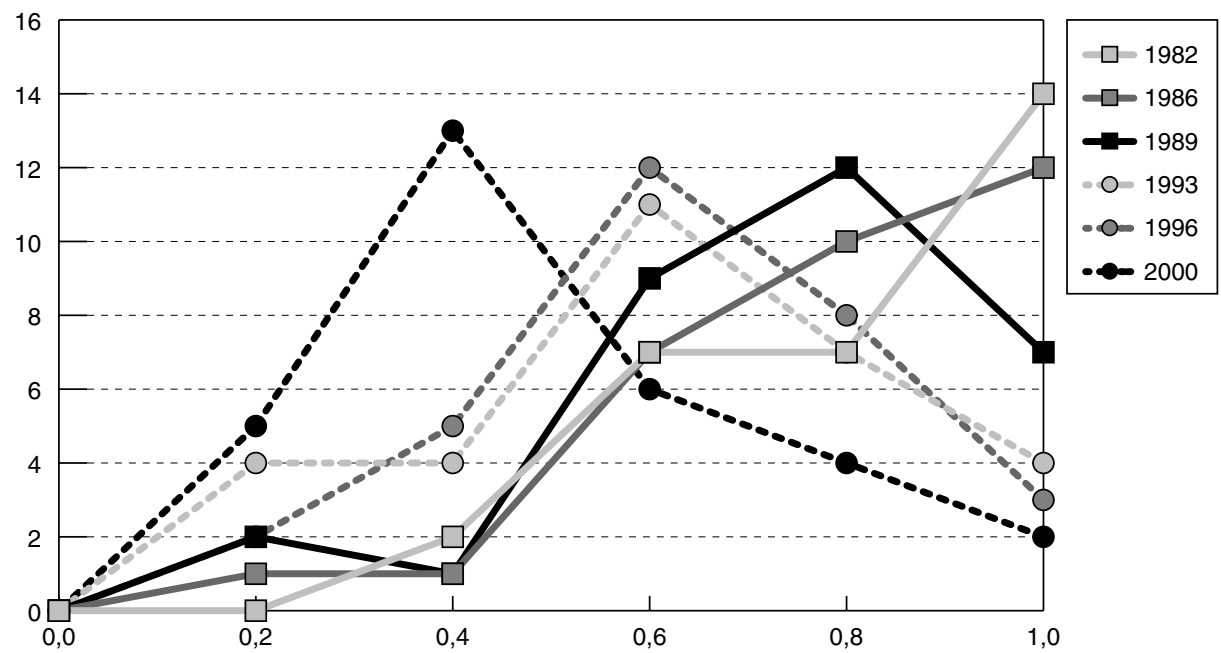


El gráfico 4 permite observar con toda claridad el distinto carácter, unimodal y bimodal, de las distribuciones del índice SF en los comicios de cada década (años ochenta y años noventa). La elección de 2000 es la que registra unas frecuencias del índice SF más próximas al valor 0: se trata de la convocatoria en la que mayores situaciones de equilibrio duvergeriano se han registrado de todos los procesos analizados y, por tanto, en la que mejores condiciones - aparentemente - se habrían dado para que una parte significativa de los ciudadanos optaran por hacer un uso estratégico de su voto: los votantes podían intuir fácilmente que el PP se haría con la victoria electoral, aunque se desconocía el grado de tal victoria; la consecución de la abultada mayoría absoluta de escaños del PP fue una sorpresa para gran parte del electorado. Por otro lado, un buen número de quienes votaron por IU en 1996 podían sentirse en el año 2000 decepcionados o descontentos con la deriva que la coalición venía siguiendo en los últimos años, a juzgar por lo evidenciado por los sondeos preelectorales. Adicionalmente, el pacto preelectoral celebrado apresuradamente entre PSOE e IU pocos días antes de las elecciones podría haber incitado a ex votantes de IU a optar por el PSOE para evitar una victoria más abultada del PP, que era el objetivo implícito del PSOE, por mucho que se abstuviera de manifestarlo explícitamente.

El análisis del Estudio postelectoral del CIS arroja algo de luz en este sentido. Como se ha puesto de manifiesto en otro lugar (García Ferrando y Oñate, 2004), el grado de fidelidad del voto de IU se redujo considerablemente en estos comicios, al pasar del $80 \%$ a poco más del $50 \%$. También se reduce su capacidad para movilizar a antiguos abstencionistas (pasó de hacerse con el voto del $15 \%$ de quienes se habían abstenido en la anterior elección a conseguir sólo el del $5 \%$ de este tipo de electores). De forma complementaria, el análisis de las transferencias de voto declaradas por los entrevistados apunta en el mismo sentido: el volumen de voto transferido de IU al PSOE se ha mantenido prácticamente igual que en comicios anteriores (en torno al 0,8 del censo de la elección anterior), mientras que el voto a la coalición se ha reducido a la mitad. Además, el porcentaje de quienes decían estar dispuestos a votar por una segunda fuerza política (de la que no se sentían tan cercanos como respecto de su favorita) si ello servía para evitar la victoria de un partido que les desagradaba era mayor (en más de seis puntos) entre los ex votantes de IU que entre los de otras fuerzas políticas ${ }^{27}$.

Estas cifras, así como la distribución de frecuencias del índice SF, apuntan a un incremento del uso del voto estratégico en las elecciones de 2000. Se comprueba, así, que existe una relación directa entre el grado de competitividad (de la victoria misma o del margen de ésta) percibida antes de la contienda electoral y la utilización estratégica del voto en los distritos pequeños en los que se distribuyen cinco o menos de cinco escaños.

27 Similar porcentaje se registraba en el País Vasco entre los ex votantes de Eusko Alkartasuna (formación que suele ocupar una posición de «perdedor», como IU), según datos del Estudio 2382 del CIS. 
La última hipótesis que queremos cotejar es la relativa a la relación entre el carácter par o impar de la magnitud del distrito y la utilización estratégica del voto. Dada la fórmula electoral utilizada (fórmula D’Hondt), que se reparta un número par o impar de escaños puede tener consecuencias significativas para la proporcionalidad y, por ende, para la mayor o menor utilización estratégica del voto. La hipótesis que cabe formular en este sentido es que en distritos con número impar de escaños a repartir habrá una mayor utilización estratégica del voto que en aquellos en los que el número de escaños a repartir sea par. Lo lógico sería agrupar los distritos según el carácter par/impar de su magnitud, pero dadas las considerables diferencias que se han observado entre los valores del índice SF de los distritos pequeños y los de los grandes, convendrá hacer la doble distinción para apreciar mejor la eventual incidencia de la variable «carácter par/impar del número de escaños a distribuir».

GRÁFICO 5

Distribución del índice SF según tamaño del distrito (par/impar, pequeño/grande), 1982-2000, en porcentaje respectivo

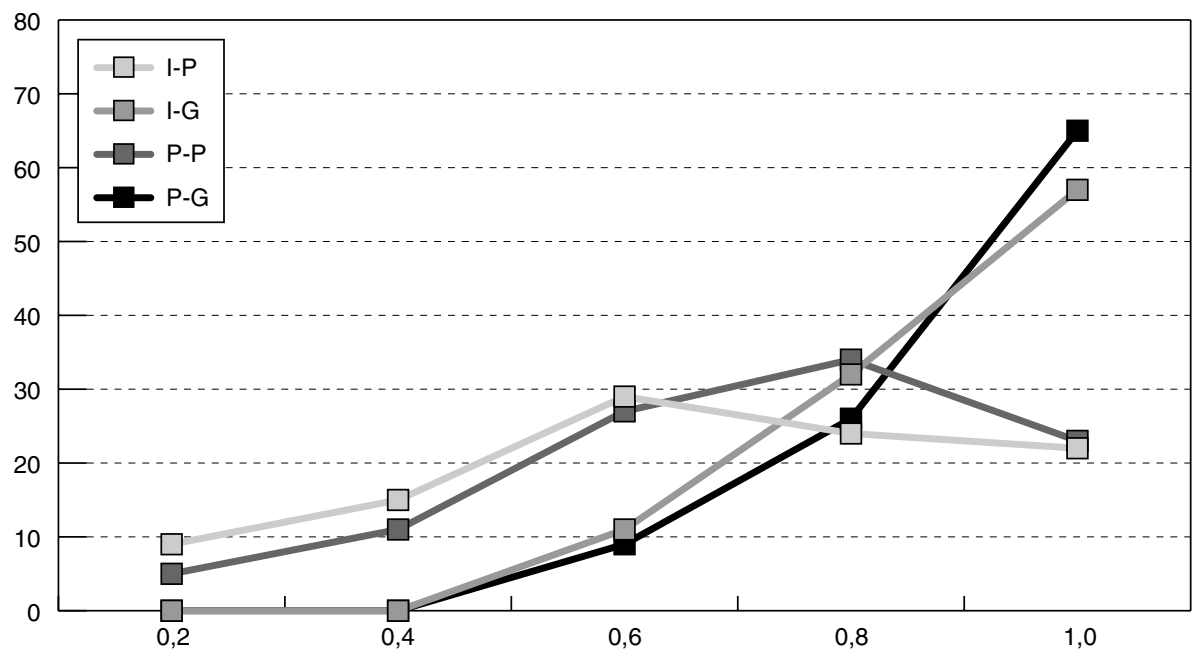

El gráfico 5 permite apreciar que apenas hay diferencias entre los valores del índice en los distritos con magnitud par o impar, siguiendo sus respectivas distribuciones de índice SF tendencias paralelas. Sí se observan disparidades significativas, como se mencionó con anterioridad, entre los distritos pequeños y grandes. Pero si se atiende en cada uno de esos tipos de distrito a las diferencias debidas a su carácter par/impar, se comprueba que 
la variación entre las respectivas distribuciones del índice SF son escasas, si bien homogéneas: a la luz del gráfico 5 , en los distritos con número impar de escaños es más probable que se registre voto estratégico en mayor medida que en aquellos en los que se distribuye un número de escaños par. La distribución del último escaño suele ser la que introduce los mayores sesgos desproporcionales, por lo que los partidarios de terceras fuerzas pueden tender a preferir otorgar su voto a su segunda opción y que esta segunda opción gane el escaño impar en el distrito (colaborando a que no se haga con él la formación ubicada en el otro lado del espectro ideológico). El carácter par/impar de la magnitud del distrito es poco relevante a efectos de la utilización estratégica del voto, aunque se observa sistemáticamente que ha habido algo más de voto estratégico en los distritos con número impar de escaños a repartir.

\section{CONCLUSIONES}

En las páginas anteriores hemos tratado de indagar acerca de la medida en la que podemos decir que en España existe relación entre la variable institucional constituida por el sistema electoral, y más en concreto el tamaño del distrito, y la decisión del votante. Hemos analizado las distintas formas propuestas para medir la presencia de voto estratégico en las elecciones generales, entendiendo (con Duverger) que este tipo de efecto es una consecuencia psicológica del sistema electoral: algunos de los electores que se sienten cercanos a un partido político que no va a lograr grandes resultados en las urnas optan por no votarle al anticipar que no tiene posibilidades reales de obtener representación, prefiriendo desplazar su voto hacia otro partido del que no se sienten tan cercanos pero que, en su opinión, sí tiene opciones reales de lograr escaños. Con ello, estos votantes instrumentales procuran no desperdiciar su voto, reforzando su segunda opción y evitando, quizás, que gane otra fuerza política de la que no se sienten cercanos en absoluto. Por este motivo se ha dado a este fenómeno el nombre de voto útil, voto estratégico o voto sofisticado.

La forma más sencilla para medir la elusiva presencia del voto estratégico en el comportamiento electoral de los ciudadanos parte de la agregación de los distritos en función de su tamaño para comparar los respectivos promedios que se registran en ellos del índice de número efectivo de partidos. Cabe pensar que al agrupar los distritos por su tamaño se excluye la eventual incidencia que las variables política y geográfica podrían tener en el valor del mencionado índice. Las diferencias entre los promedios de los índices de los diversos tipos de distritos pueden explicarse, por tanto, por la utilización que hacen los votantes de los distritos pequeños del voto estratégico: los electores de esos distritos votan en menor medida por los partidos pequeños puesto que saben o intuyen que difícilmente lograrán representación. Prefieren no desperdiciar su voto y lo otorgan a una de las dos fuerzas políti- 
cas que, prevén, conseguirán representación. Hemos comprobado que en los distritos pequeños se ha registrado sistemáticamente un índice del número efectivo de partidos menor que en los distritos grandes, en los que las pequeñas formaciones tienen más posibilidades (así lo perciben los electores) de conseguir representación. Esa tendencia se ha mantenido en la elección de marzo de 2000, pese a las excepciones registradas en Ceuta y Melilla, pero que se explican por los motivos aducidos (transferencia de voto por el descontento con los partidos tradicionales a otros nuevos).

No obstante, el análisis practicado con el segundo enfoque metodológico propuesto para abordar la cuestión del voto debilita la evidencia surgida de la primera aproximación, al obligarnos a dudar de que la menor fragmentación (número efectivo de partidos) registrada en los pequeños distritos se deba a la influencia del sistema electoral en los votantes (que se trate de un efecto psicológico del sistema electoral).

Este segundo enfoque propone comparar los porcentajes que se registran en los distritos pequeños y grandes de ciudadanos que habiendo dicho sentirse cercanos a una pequeña formación, o que autoubicándose en posiciones ideológicas coincidentes con las que ocupa ese partido, acaban efectivamente confiriéndole su voto. Hemos constatado que las diferencias entre el apoyo que recibe este tipo de formación (hemos atendido al caso de IU) en uno y otro tipo de distrito se explican, más que (o además de) por una utilización estratégica del voto, por contar en los distritos grandes con un porcentaje mayor de ciudadanos que dicen sentirse cerca de ese partido, o que se ubican en similar posición ideológica a la que ocupa el partido, que en los pequeños. La diferencia que Gunther atribuía a una utilización estratégica del voto se explica, en realidad, por existir un mayor porcentaje de partidarios de IU en los distritos grandes: se niegan los presupuestos de la hipótesis ex ante. De esta forma, el fenómeno que Gunther comprobó para las singulares elecciones de 1979 y 1982 no parece confirmarse cuando se analizan todos los procesos electorales celebrados desde esta última convocatoria. No obstante, se han utilizado datos de encuesta de estudios postelectorales en los que podría darse un sesgo introducido por los electores en un intento de adecuar su respuesta en cuanto a cercanía de partido y ubicación ideológica al comportamiento político realizado pocos días antes en la votación, generándose una imagen de coherencia ex post tendente a evitar disonancias con el sentido del voto emitido.

Una tercera forma de medir la presencia de voto estratégico en nuestros procesos electorales es la propuesta por Cox, acudiendo al índice SF (second/first), que tiene en cuenta la ratio entre el cociente del segundo partido y el del primer partido perdedores al otorgarse el último escaño a distribuir en cada distrito. Agregando los valores de los índices en atención al tamaño del distrito, observamos que se registran, igualmente, diferencias entre los correspondientes a los distritos pequeños y los de los grandes. En los distritos pequeños, los 
valores se encuentran más próximos al 0 , experimentando una distribución bimodal, mientras que en los distritos grandes se da una de carácter claramente unimodal, con tendencia a la acumulación de valores cerca del 1. Ello es indicio de que los votantes de los distritos grandes optan en mayor medida por terceros y cuartos partidos que los de los distritos pequeños. Al agruparse los distritos en función de su tamaño, con independencia de sus respectivas tendencias políticas y de su ubicación geográfica, creemos que esas diferencias se explican por la variable institucional que los distingue, esto es, por su distinta magnitud o tamaño (el número de escaños que se reparte en cada uno):

a) pequeños, en los que — dados los sesgos desproporcionales que se generan — no habrá más de dos partidos, generalmente, que tengan posibilidades reales de obtener representación;

b) grandes, en los que más de dos partidos tendrán opciones efectivas de lograr representación.

Hemos comprobado que existen las condiciones para aplicar este enfoque metodológico a las elecciones generales celebradas en nuestro país, al constatar que los problemas que observaba Cox son menores de lo que él mismo pensaba. Por otro lado, estudiando más procesos que los que él analizó, estamos en condiciones de distinguir la medida en la que se pudo hacer una utilización estratégica del voto en distintas coyunturas políticas: a) menor en las elecciones de 1982, 1986 y 1989, por la mayor certidumbre acerca de la victoria -y su grado- del PSOE y la menor importancia relativa que los electores, individualmente, podían conferir a su voto para el resultado global, a la vista de los sondeos; b) mayor en las elecciones de 1993, 1996 y 2000, en función de la menor certidumbre sobre qué partido acabaría ganando la elección (o, para la de 2000, cuál sería el grado de esa victoria): cobraba mayor relevancia el voto de cada elector al ser el resultado acerca de la victoria más incierto.

Hemos comprobado, por tanto, que las condiciones para una mayor utilización estratégica del voto se corresponden con un distrito de tamaño pequeño y en una coyuntura en la que la victoria en los comicios -o su grado - sea difícilmente previsible para el elector. Por último, la evidencia presentada no permite afirmar que exista una importancia significativa del carácter par o impar del número de escaños a repartir en el distrito, a efectos de este análisis. Pese al distinto grado de desproporcionalidad que esa diferencia implica para cada distrito, de ello no se derivan consecuencias importantes para el comportamiento de los votantes. En todo caso, siendo pequeña la diferencia, se confirma que la mayor proporcionalidad (provocada por el carácter impar del tamaño del distrito, especialmente en los de carácter pequeño) da lugar a una utilización algo mayor del voto estratégico. 
Hay que concluir, por todo ello, que la variable institucional constituida por el sistema electoral español y sus considerables sesgos desproporcionales -más acusados en los distritos pequeños que en los grandes - tiene incidencia en la decisión de los votantes: la desproporcionalidad que se genera en los distritos pequeños y la consiguiente infrarrepresentación de los pequeños partidos pueden ser percibidas o intuidas por los electores con anterioridad a cada proceso electoral (por su experiencia electoral, por lo que anuncian los sondeos o los medios de comunicación o por lo que transmiten los partidos en la campaña electoral), y esto puede conducirles a variar su comportamiento en el sentido de intentar que su voto no sea desperdiciado. No obstante, a juzgar por el carácter bimodal de la distribución de frecuencias del índice SF, buena parte de los votantes de los pequeños partidos (en nuestro caso, de IU) no consideran que desperdician su voto otorgándolo a la formación aun cuando intuyen que no servirá para que ésta logre representación: se trata de votantes no instrumentales. El fenómeno consistente en que una parte significativa del electorado de los distritos pequeños adopte un comportamiento estratégico, para dotar de mayor valor a su voto, al objeto de conseguir que la opción por la que se decantan logre representación o que aquella de la que se sienten muy distantes consiga menos escaños en el distrito, es poco frecuente cuando la elección no está muy reñida o cuando la victoria por mayoría absoluta de una formación es predecible. El fenómeno es más frecuente cuando no se dan estas condiciones. Las circunstancias que rodearon la elección de marzo de 2000 hicieron que se registraran en ella los valores más bajos del índice SF en los distritos pequeños de todos los procesos electorales analizados, lo que es un indicio del incremento de la utilización del voto estratégico. La información aportada por los estudios demoscópicos de carácter postelectoral avala la evidencia aportada.

Todo ello permite confirmar que el tamaño del distrito incide en la decisión de los votantes españoles, aunque tal vez en menor medida de lo que en algunas ocasiones se ha afirmado. Con los instrumentos de los que hoy disponemos no es posible cuantificar más de lo que lo hemos hecho la medida de esa influencia. A buen seguro, futuros estudios que analicen nuevos casos en los que concurran distintas circunstancias facilitarán esta tarea, que en estas páginas no hemos hecho sino iniciar.

\section{REFERENCIAS BIBLIOGRÁFICAS}

ANDUIZA, Eva, y OÑATE, Pablo (2004): «Los efectos de la campaña electoral de marzo de 2000 sobre los electores», en I. Crespo (ed.), Las campañas electorales y sus efectos en la decisión del voto: La campaña electoral de 2000; partidos, medios de comunicación y electores, Valencia, Tirant lo Blanch (395-438).

BLAYS, André, y CARTY, R. K. (1991): «The Psichological Impact of Electoral Laws: Measuring Duverger's Elusive Factor ", British Journal of Political Science, 21 (79-93). 
COX, Gary W. (1984): «Strategic Electoral Choice in Multi-Member Districts: Approval Voting in Practice?», American Journal of Political Science, 28 (722-738).

COX, Gary W. (1997): Making Votes Count. Strategic Coordination in the World's Electoral Systems, Cambridge, Cambridge University Press.

CRESPO, Ismael; MARTÍNEZ, Antonia, y OÑATE, Pablo (2004): « ¿Tienen las campañas electorales efectos sobre la decisión del elector? », en I. Crespo (ed.), Las campañas electorales y sus efectos en la decisión del voto: La campaña electoral de 2000; partidos, medios de comunicación y electores, Valencia, Tirant lo Blanch (496-521).

DUVERGER, Maurice (1972): Los partidos políticos, México, Fondo de Cultura Económica.

GARCÍA FERRANDO, Manuel, y OÑATE, Pablo (2004): El cambio electoral en España: transferencias de voto a la luz de los estudios postelectorales, manuscrito.

GUNTHER, Richard (1989): «Leyes electorales, sistemas de partidos y elites: el caso español», Revista Española de Investigaciones Sociológicas, 47 (73-106).

LAGO, Ignacio, y LAGO, Santiago (2000): «El sistema electoral español: una cuantificación de sus efectos mecánico y psicológico», Revista de Estudios Políticos, 107 (225-250).

LIJPHART, Arendt (1994): Electoral Systems and Party Systems. A Study of Twenty-Seven Democracies, 1945-1990, Oxford, Oxford University Press.

MONTERO, José R., y VALLÉS, Josep M. (1992): «El debate sobre la reforma electoral: ¿para qué las reformas?», Claves de Razón Práctica, 22 (2-11).

OÑATE, Pablo (2002): «El sistema electoral y voto estratégico», en I. Crespo (ed.), Las campañas electorales y sus efectos en la decisión del voto: La campaña electoral de 2000; partidos, medios de comunicación y electores, Valencia, Tirant lo Blanch (198-220).

OÑATE, Pablo, y OCAÑA, Francisco (1999): Análisis de datos electorales, Madrid, Centro de Investigaciones Sociológicas.

- (2000): «Elecciones de 2000 y sistemas de partidos en España: ¿Cuánto cambio electoral?», Revista de Estudios Políticos, 110 (297-336).

- (2005): «Las elecciones generales de marzo de 2004 y los sistemas de partidos en España: ¿tanto cambio electoral?», Revista Española de Ciencia Política (en prensa).

RAE, Douglas R. (1971): The Political Consequences of Electoral Laws, New Haven, Harvard University Press.

RIVA, Clara, y PADRÓ-SOLANET, Albert (1985): «Strategic Voting Behavior in Proportional Electoral Systems: The Case of Spain», paper presentado en la 1995 ECPR Joint Session of Workshops, Burdeos.

SARTORI, Giovani (1968): «Political Development and Political Engineering», en John D. Montgomery y Albert Hirschman (eds.), Public Policy, vol. XVII, Cambridge, Harvard University Press.

- (1987): Partidos y sistemas de partidos, Madrid, Alianza.

- (1994): Comparative Constitutional Engineering: An Inquiry into Structures, Incentives and Outcomes, London, MacMillan.

SHIVELY, W. Phillips (1970): «The Elusive "Psicological Factor”. A Test for the Impact of Electoral Systems in Voter's Behavior», Comparative Politics, 3 (115-125).

TAAGEPERA, Rein, y SHUGART, Matthew S. (1989): Seats and Votes. The Effects and Determinants of Electoral Systems, New Haven, Yale University Press. 
This paper analyses the psychological effects of the electoral system, paying attention to the influence that the size or magnitude of the electoral district has on the strategic use of the vote in the Spanish Congreso de los Diputados elections. In order to measure the incidence of the strategic vote on the behaviour of Spanish voters between 1982 and 2000, the various approaches proposed for studying this phenomenon are applied. The results make it possible to confirm that the institutional variable forming the electoral system - the size or dimension of the district, in other words the difference between large and small districts - has an influence on the behaviour of voters.

Key words: Strategic Vote, Useful Vote, Electoral Behaviour, Electoral System, Elections. 